\title{
An Analysis of Students' Mathematical Competencies: The Relationship between Units
}

\author{
Jitlada Jaikla ${ }^{1,2}$, Maitree Inprasitha ${ }^{1,2}$ \& Narumon Changsri ${ }^{1,2}$ \\ ${ }^{1}$ Mathematics Education Program, Faculty of Education, Khon Kaen University, Thailand \\ ${ }^{2}$ Center of Excellence in Mathematics, CHE, Si Ayutthaya RD., Bangkok, Thailand \\ Correspondence: Maitree Inprasitha, Mathematics Education Program, Faculty of Education, Khon Kaen 40002 , \\ Thailand. E-mail: inprasitha_crme@kku.ac.th
}

Received: May 5, 2021; Accepted: June 16, 2021; Published: June 18, 2021

\begin{abstract}
This study aimed to investigate students' mathematical competence in learning relationships between units according to the students' performance in a SUKEN test of Level 6. A total of 139 students were selected as our target group and involved as examinees. Research instruments include students' answer sheets, test item analyses, and textbook analysis. SUKEN test is a mathematical proficiency test used to identify related issues to improve teaching practices. The results from the first phase showed that there were 24 examinees or 17.27 percent of them had been successfully passed the passing criterion as 70 percent of the total marks 100 . However, there was a lowest percentage (33.21\%) of examinees showed that they were able to answer correctly in the questions related to the content domain of Quantities and Measurement compared to other content domains. On top of that, only 38.49 percent and 31.09 percent of the examinees possessed their competencies in content knowledge and the method of application respectively while they answered the Quantities and Measurement questions. Besides, the results of in-depth analyses from students' answer sheets revealed that there were seven different groups of answers by analyzing examinees' responses in terms of their reasoning skills to support their responses. Examinees were found to have problems finding the relationship between $\mathrm{cm}^{3}$ and $\mathrm{m}^{3}$, whenever they have to use a relationship in three dimensions. Therefore, teachers are suggested to use the geometry model to assist students in understanding the relationships between the units.
\end{abstract}

Keywords: mathematical competencies, Quantities and Measurement, relationship between units, SUKEN test

\section{Introduction}

The Program for International Student Assessment (PISA) is organized by the Organization for Economic Cooperation and Development (OECD) to measure 15 years old abilities in utilizing their reading, mathematics, and science knowledge and skills to meet real-life challenges. The study report of PISA from 2000 to 2012 by the Institute for the Promotion of Teaching Science and Technology: IPST in Thailand, revealed that the trend of results in mathematics literacy among Thai students showed a continuous decline. Thai students are found particularly weak in the content of change of quantity and its relationships, as reported by the Institute for the Promotion of Teaching Science and Technology (2014). This measurement spans both subjects, namely mathematics and science and acts as a root of our daily experience (Gravemeijer, 1998 cited in Leher, 2007). However, traditional teaching was failed to relate student learning to their real-world experiences. As a result, this study designed to investigate students' mathematical competence in learning relationships between units.

In particular, in the PISA 2012, it was found that Thai students had the greatest weaknesses in these two aspects, namely, change and relationships, and quantity. Both aspects are related to the content domain of Quantities and Measurement (IPST, 2014). The continued decline in the PISA score may reflect that the problem has been accumulated over a long period of time since primary school. In Thailand, there is an examination that uses the ordinary national education test (O-NET) to assess the learning progress of all students who have studied in the final year of all four levels of class, namely, Grade 3, Grade 6, Grade 9, and Grade 12 (Lincharoen, Artwichai, \& Chanin, 2009), together with some scholars who found that the teaching and learning approaches in schools and the guidelines for designing tests or assessing guidelines were not corresponding to understand and improve their mathematical competencies (Chittradub, 2009).

The Mathematical Competency Certification Institute of Japan (MCIJ) organized a mathematical competency test, so-called SUKEN test to assess students' mathematical competencies. SUKEN is a test with basic principles of 
problem development scope and test structure as follow: (i) Problems related to content knowledge requirements to understand contents of the higher grades therefore demanded the useful knowledge and skills in student's daily lives and (ii) problems related to applying knowledge and skills that students learned in daily lives. For example, problem-solving through working out plans, evaluating, and improving the process as well as the results (Shimizu, 2015). Hence, SUKEN test has been developed by Japanese experts who possess a comprehensive understanding of the content of the curriculum for more than 25 years. Moreover, the feature of the test is to ask students to write responses, which can be used to in-depth analyze the concept of solving problems of the students who pass the examination. Therefore, SUKEN test can be used in corresponding to the needs of society change in the 21 st century. As a result, SUKEN test is no doubt can be used to measure students' mathematical competencies by transferring knowledge into practice through students' responses (Inprasitha, 2017). In 2017, the Mathematical Competency Certification Institute of Thailand (MCIT) in collaboration with MCIJ organized a mathematical competency test in Thailand. There are a total of 11 levels of SUKEN test in Thailand, namely, the level 11-6 will be knowledge equivalent to elementary school while the level 5-3 will be knowledge equivalent to junior high school (Inprasitha, 2017).

In addition, the continual decline in PISA scores is reflected that the teaching that takes place in the classroom is still unable to improve the student's critical thinking process as it should be (Santawee, 2014). Many scholars have mentioned about teaching approach that requires students' daily life experiences in designing problem situations for students to realize real learning (Kesorn, Junpeng, Marwing, Pongboriboon, Tang, \& Wilson, 2020). They noted that mathematics teachers in Thailand are generally not linking students' daily life experiences to solve mathematical problems in their teaching. Most of them are using product-based teaching, that is teachers are lecturing the mathematical content. Gravemeijer (1998 cited in Leher, 2007) noted that measurement is an endeavor that spans both subjects, namely mathematics and science besides its roots in our daily experience. Later, previous researchers have reorganized and comprehended these daily experiences using the modeling and measuring aspects of space. Leher (2007) noted that measurement consists of a measure's dual qualities of practical grasp and imaginative reach.

The National Council of Teachers of Mathematics (2000) emphasized that teaching measurement has to begin with students' experiences in their daily lives to assist them to have a better understanding in learning properties and the meaning of measurement. Before teachers use the tools to enhance students' understanding of measurement in area or volume, they are encouraged to use the model for representation (Kerr \& Lester, 1976). This is further supported by the National Council of Teachers of Mathematics (2000). The National Council of Teachers of Mathematics highlighted the importance of linkage between the other two domains, namely geometry and number to teach measurement in mathematics at the school level.

Thailand's education system has still lacked a systematic review of the national curriculum holistically. The "curriculum" is focused on only documentation without emphasizing the implementation aspect. In short, the curriculum "process" is not given sufficient attention and "systematic" learning is emphasizing on "product" based paradigm with the lack of substantial understanding of the curriculum itself. In this line of reasoning, we need to consider seriously mathematical competency in problem-solving learning for the systematic relationship by reforming curriculum and being effective teaching and learning instead of studying what is appeared in the course materials (Inprasitha, 2015; The Committee on Education and Sports, The National Legislative Assembly, 2015).

According to Kilpatrick (2009: 109), the course components consist of three levels, namely intended curriculum, implemented curriculum, and attained curriculum. The Committee on Education and Sports, The National Legislative Assembly (2015), and Inprasitha (2015) proposed a new model of conducting mathematics curriculum and instructional organization in Thailand context. The main idea of curricular reformation is complementing the top-down approach with the bottom-up approach using research and development activities. This is to close the gap between each level of the curriculum, as shown in Figure 1. This idea is supported by Shimizu (2011), who emphasized the importance of external or large-scale assessments to improve teaching in Japan. Furthermore, Swan and Burkhardt (2012) highlighted the importance of large-scale assessments in providing messages to teachers regarding the values of curriculum that impacting both instruction and assessment activities in their teaching. Therefore, Swan and Burkhardt (2012), and Inprasitha (2015) believe that curriculum and instruction should be directed towards assessment. When considering the composition and the relationship between each level, there are some improvements about curriculum and textbooks are needed, but there is still a lack of clear guidance or the process of developing knowledge and understanding for teachers, as their role is being textbook users and has the primary responsibility for teaching and learning in the classroom (Inprasitha, 2015; The National Legislative Assembly, 2015; Senawongsa, 2019). This is corresponding to the Trends in International Mathematics 
and Science Study (TIMSS) survey which found that the majority of mathematics teachers are using textbooks as the main written source when they selected teaching approaches (Fan \& Zhuo, 2007).

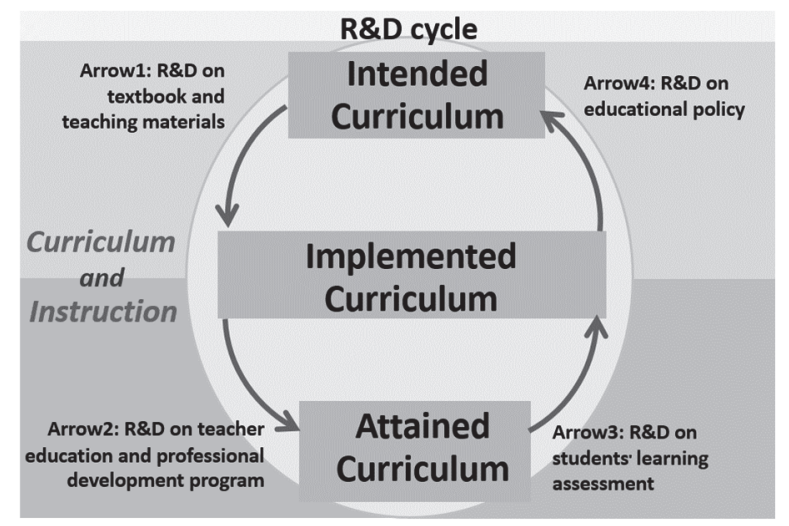

Figure 1. A New Model of Conducting Mathematics Curriculum and Instructional Organization in Thailand Context (Source: Inprasitha, 2015)

The SUKEN mathematical competency test is a large-scale assessment not only provided measurement of mathematical competencies for the $21^{\text {st }}$ century educational needs but also an appropriate tool to provide feedback for teaching improvement. Table 1 illustrates the structure and contents of SUKEN test of Level 6.

Table 1. Structure and contents of SUKEN test of Level 6

\begin{tabular}{|c|c|c|c|}
\hline No. & Content domain & Sub-topic & Total of questions \\
\hline 1. & $\begin{array}{l}\text { Numbers and } \\
\text { Calculations }\end{array}$ & $\begin{array}{l}\text { Multiplication and division of fractions } \\
\text { Consolidating computation skills with decimal numbers } \\
\text { and fractions }\end{array}$ & 13 \\
\hline 2. & Geometry Figures & Reduced and enlarge figures, and symmetric figures & 2 \\
\hline 3. & $\begin{array}{l}\text { Mathematical } \\
\text { Relations }\end{array}$ & $\begin{array}{l}\text { Ratio } \\
\text { Proportional relationships } \\
\text { Algebraic expressions with letters } \\
\text { Analyzing data } \\
\text { Possible outcomes }\end{array}$ & 8 \\
\hline 4. & $\begin{array}{l}\text { Quantities and } \\
\text { Measurement }\end{array}$ & $\begin{array}{l}\text { Approximates shapes and estimated area } \\
\text { Area of a circle } \\
\text { Volume of prisms and cylinders } \\
\text { Speed } \\
\text { Relationship between units }\end{array}$ & 7 \\
\hline & Total & & 30 \\
\hline
\end{tabular}

\section{Aim of the Study}

This study was aimed to analyze the results from the mathematical competency test (SUKEN test) of Level 6 to improve the teaching practices.

\section{Method}

\subsection{Study Design and Samples}

The SUKEN is a Global Mathematics Certification program and examination established in Japan since 1988. Each SUKEN test has two sections, namely, Section 1 is a calculation so-called as knowledge competency and Section 2 is application competency. Each candidate is required to answer correctly 70 percent of Section 1 and 60 percent of Section 2 in order to pass the SUKEN test. The examination duration is 60 minutes and 120 minutes for Section 1 and Section 2 respectively. There were more than 350,000 individuals from all ages have taken SUKEN tests every year since 2015, with approximately 17,000 educational institutions participated in the SUKEN test. Owing to SUKEN test is a nationwide mathematical competency test and has its absolute evaluation 
system, it is useful to use as a standardized test to measure mathematical ability proof needed for further studies or job qualifications. SUKEN tests not only conducted in Japan but also in the Philippines, Thailand, Cambodia, and others (Isoda, 2010).

The research methodology employed in this study was a multi-phase design encompassing two phases: In Phase 1, the researchers used a quantitative approach by asking students to take the SUKEN test. Then, the test results were analyzed using the item analysis method for each item to identify students' mathematical competencies. In Phase 2, qualitative research using in-depth analysis was employed to the answers of test results to identify issues that related to assisting in teaching improvement.

The target group of this study was 139 students aged between 12 to 15 years old using the purposive sampling technique. This is because students aged between 12 to 15 years old or before adulthood is the period that they begin to think abstractly and logically on more complex matters, the so-called formal-operational stage in accordance with Piaget's theory of cognitive development. Therefore, students at this age range should be fully developed so that they can think logically and solve mathematical problems up to their readiness to become a mature adult.

\subsection{Study Procedure}

Four content domains are being measured in the SUKEN test of the Level 6 framework to examine test takers' mathematical competencies. The study procedure is presented as follows:

(i) The researchers used a document analysis approach to analyze the SUKEN tests by MCIT in Thailand found that there are 11 levels of SUKEN test, where level 11-6 will be knowledge equivalent to elementary school while level 5-3 will be knowledge equivalent to junior high school. The SUKEN test is a test to assess the student's content knowledge and skills, and application of knowledge and skills. Moreover, document analysis found that the previous SUKEN tests of Level 6 are mainly cater to students' knowledge equivalent to Grade 6 to Grade 7 or aged from 12 to 13 years old for the past two years. The selection of Level 6 because the previous SUKEN test performance showed that examinees possessed the lowest mathematical competencies as they had the lowest percentage of passing the criteria. Moreover, researchers took into consideration of four stages of Piaget's theory of cognitive development while researchers were designing the research tool, which is a mathematics competency test of Level 6 (SUKEN test). Moreover, the feature of the test is to ask students to write responses, which can be used to analyze the concept of solving problems of the students who pass the examination.

(ii) A total of 30 questions from the original SUKEN test were translated from English to the Thai language by language experts.

(iii) The translated SUKEN test was reviewed by mathematics education experts in terms of content validity and the suitability to Thailand context.

(iv) The developed research tool was piloted to graduate students to examine the content and language validity as well as its reliability.

(v) After the pilot study had been conducted, the research tool was modified and made necessary adjustments by researchers in corresponding to the feedback received from the pilot study.

\subsection{Data Collection}

The researchers started to collect data in January 2019 following two phases of study procedure as follows:

(i) The research tool was the SUKEN test that was used to assess the student's content knowledge and skills, as well as applying knowledge and skills. At the first phase, researchers examined all content domains, namely, Numbers and Calculations, Geometry Figures, Mathematical Relations, and Quantities and Measurements. However, researchers only investigated specifically on the seven questions of Quantities and Measurement content domain at the second phase. The developed mathematical competency test (SUKEN test) of Level 6 consisted of 30 questions (Quantities and Measurements content domain $=7$ questions) that were used as a research tool to measure examinees' mathematical competencies. Moreover, in the examination, examinees write their answers on answer sheets for in-depth analysis.

(ii) The researchers organized an examination committee meeting to determine the examination procedure.

(iii) The 180-minutes SUKEN test was organized and invigilated by two examiners for each room. It was conducted in a closed system without allowing any unrelated individual to enter the examination room.

(iv) After the completion of the SUKEN test, the 139 test scripts were marked by experts from the Mathematics Certification Institute of Thailand (MCIT) and the Mathematics Certification Institute of Japan (MCIJ). 


\subsection{Research Tool and Data Analysis}

Four content domains were being measured in the research tool using the SUKEN test of Level 6 framework to examine test takers' mathematical competencies. These four content domains: (i) Number and Calculations content domain consists of topics such as multiplication and division of fractions; addition, subtraction, multiplication, division, decimals, and fractions; these numerical computation skills are further strengthened to enhance their application capabilities; properties of even numbers, odd numbers, multiplication factors, and the notation system for multiplication and division of integers and decimals.

(ii) Geometrical Figures content domain is comprised of topics namely equality of triangles; symmetry; the plane of polygon and the shape of a prism and a cylinder and relationship of numbers and properties of geometric figures.

(iii) Mathematical Relations content domain is composed of topics namely simple proportional relationship, proportional relationship, proportional correction, inverse; algebraic expression (variable); data management, mean, distribution of data, data analysis for probability, algebraic expressions showing quantitative, and percentage relationships and charts.

(iv) Quantities and Measurements content domain includes topics such as finding the area of a triangle, parallelogram, rhombus, and trapezoid; unit of volume, finding the volume of a cube and a rectangular prism; finding the volume per unit; the area of a circle, determination of the volume of a cylinder and a prism; finding the speed, and metric system.

On the other hand, the research tool was designed to measure two levels of mathematical competency. The first level of mathematical competency refers to knowledge and skills that are needed to proceed in their learning and for applying in their real-life situations. Moreover, the second level of mathematical competency is defined as the competencies that related not only can apply knowledge and skills to situations in the real life but also can do their planning, implementing, reflecting, and improving the plan to solve problems.

The obtained data from the research tool were analyzed using two approaches as follows:

(i) The 30 subjective questions of the research tool would add up to a total of 30 marks. The data from the research tool were presented in the form of percentages obtained from correct or wrong answers. The researchers used descriptive statistics such as percentage, mean score, maximum and minimum score, and median to analyze the data quantitatively.

(ii) In-depth analysis was conducted qualitatively to identify student's ideas to solve mathematical problems using information from the student's answer sheet. This is followed by grouping the concept of the students' ideas in solving the seven mathematical problems in Quantities and Measurements content domain.

\section{Results}

The results of this study are presented according to the research objective stated above. The study procedure of two phases indicated the results from the mathematical competency test (SUKEN test) of Level 6 as a research tool. In the first phase, researchers identified examinees' mathematical competency levels in terms of their knowledge and application using quantitative and qualitative analysis. This is followed by in-depth analysis to investigate examinees' problems in their mathematical competencies to improve teaching practices in the final phase.

\subsection{First Phase: Examinees' SUKEN Test Performance}

A total of 30 mathematical problems were displayed in the research tool, namely the SUKEN test with a passing criterion of 70 percent of the total marks. The quantitative results showed that there are 24 examinees or 17.27 percent of them have been successfully passed the passing criterion. Moreover, the average score of the overall SUKEN test is 14.87. Besides, most of the examinees obtained the total score as 20.00 and the median score was 15. The maximum score is 29 as illustrated in Table 2.

Table 2. Statistical Data Analysis in SUKEN Test of Level 6

\begin{tabular}{ccccccc}
\hline Examinees & Passer (\%) & Max & Min & Mean & Median & Mode \\
\hline 139 & $24(17.27)$ & 29 & 0 & 14.87 & 15 & 20 \\
\hline
\end{tabular}

This is followed by analyzing in detail according to the content domains. Even though the coverage of the SUKEN test of level 6 were mainly focused on the Numbers and Calculations content domain (43.33\%), students did not have problem to answer correctly the related questions $(59.44 \%)$. This is followed by 
Mathematical Relations content domain (26.67\%), and Quantities and Measurement content domain (23.33\%). The least coverage was Geometry Figures content domain (6.67\%). However, the results showed that there were the lowest percentage of examinees were able to answer correctly the questions related to Quantities and Measurement content domain (33.21\%). The results indicated that examinees' mathematical competencies in four content domains in descending order were found as follows: Geometry Figures was $62.23 \%$, Numbers and Calculations was 59.44\%, Mathematical Relations was 44.69\%, and Quantities and Measurements was 33.21 percent. This implies that examinees are having weakest competency in Quantities and Measurement content domain. Table 3 presents examinees' performance in each content domain.

Table 3. Percentage of the Correct Answers according to Content Domains

\begin{tabular}{lll}
\hline Content Domain & Percentage of Coverage & Percentage of Correct Answers \\
\hline Numbers \& Calculations & 43.33 & 59.44 \\
Geometry Figures & 6.67 & 62.23 \\
Mathematical Relations & 26.67 & 44.69 \\
Quantities and Measurement & 23.33 & 33.21 \\
\hline
\end{tabular}

Furthermore, the results of the examinees were investigated by looking into their competencies in terms of knowledge and application. Generally, the questions related to Number and Calculation content domain were more focusing on competency of knowledge (66.67\%) and competency of application (20.00\%). However, examinees did not have problems to answer the questions correctly. The results showed that examinees possessed sufficient competencies in both aspects as knowledge (62.09\%) and application (36.21\%) respectively. Thus, examinees possessed the highest mathematical competency of their knowledge in Numbers and Calculations content domain (62.09\%) but highest mathematical competency of application in Geometry Figures content domain (62.23\%). On the other hand, examinees possessed the least competency in Quantities and Measurement content domain in both knowledge (38.49\%) and application (31.09\%) compared to the other content domains. The results revealed that examinees are having problems in the content domain of Quantities and Measurements as shown in Table 4.

Table 4. Percentage of the Correct Answers according to Content Domains and Competency

\begin{tabular}{lrrrr}
\hline \multirow{2}{*}{ Content Domain } & \multicolumn{2}{c}{ Competency of Knowledge } & \multicolumn{2}{c}{ Competency of Application } \\
\cline { 2 - 5 } & Content Domain (\%) & $\begin{array}{c}\text { Competency } \\
(\%)\end{array}$ & Content Domain (\%) & $\begin{array}{c}\text { Competency } \\
(\%)\end{array}$ \\
\hline Numbers \& Calculations & 66.67 & 62.09 & 20.00 & 36.21 \\
Geometry Figures & 0 & 0 & 33.33 & 62.23 \\
Mathematical Relations & 20.00 & 59.95 & 33.33 & 34.39 \\
Quantities and Measurement & 13.33 & 38.49 & 13.33 & 31.09 \\
\hline
\end{tabular}

\subsection{Final Phase: In-depth Analysis to Improve Teaching Practices}

The results of the first phase found that 33.21 percent of the examinees are having problems in the content domain of Quantities and Measurements. In-depth analysis showed that examinees are having problems solving questions related to the relationship between units specifically. An example was elucidated in Figure 2.

$$
7,800,000 \text { cubic centimeter }=\square \text { cubic meter }
$$

Figure 2. An Example of Mathematical Problem in Quantities and Measurement Domain

The results of the in-depth analysis showed that only 16.55 percent of examinees could answer this mathematical problem correctly, as indicated in Table 5. The qualitative results found that those examinees who were able to answer correctly because they could understand the mathematical concepts and linked the measurement content with the subject matter of geometry by using dimensions to help them to visualize the volume as shown in Figure 
3. This result is found in accordance with Kerr and Lester's (1976) ideas. Kerr and Lester stated the importance of creating a model to assist the understanding of the measurement of volume before a tool is used. This is supported by the United States Council of Mathematics Teachers (2000) who emphasized the importance of linkage between learning measurement to the other two subject matters, namely geometry and numbers.

Table 5. Percentage of the Examinees' Answers

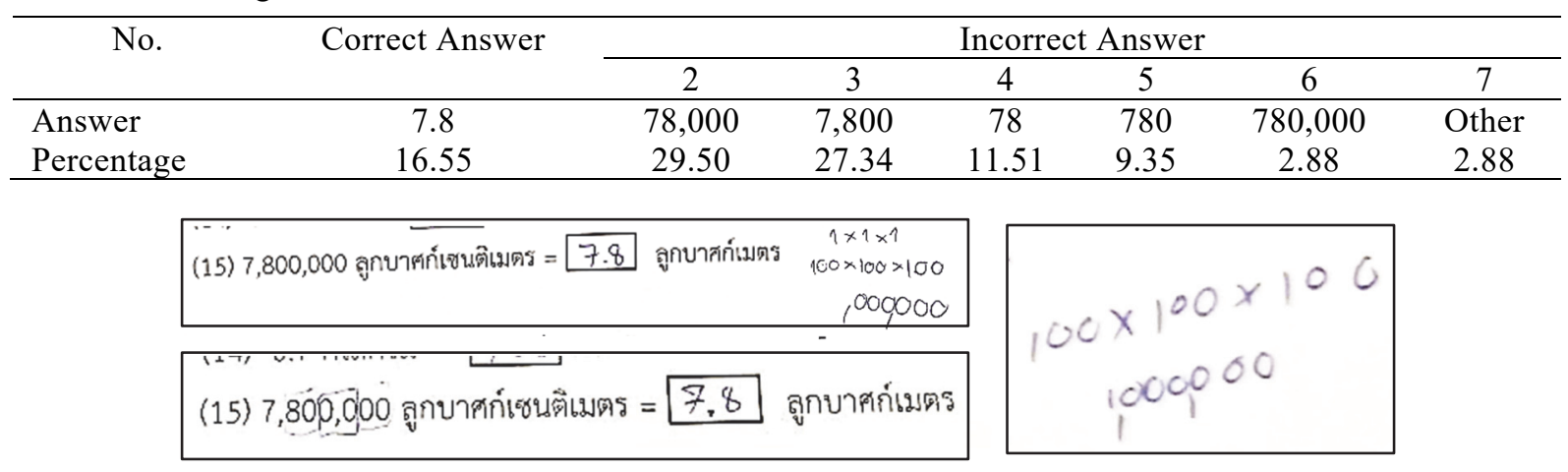

Figure 3. Examinees' Ideas from the Correct Answer

On the other hand, the qualitative results showed that most of the examinees are having problems understanding the concepts of the relationship between units. Most of them used the concept of 100 centimeters $(\mathrm{cm})$ equal to 1 meter $(\mathrm{m})$, and then divided 100 centimeters $(\mathrm{cm})$ by 7,800,000 cubic centimeters $\left(\mathrm{cm}^{3}\right)$, which is found to be a unit of the different dimensions, that is, a centimeter is a unit of length while the cubic centimeter is a unit of volume. This mistake was reflected in Figure 4.

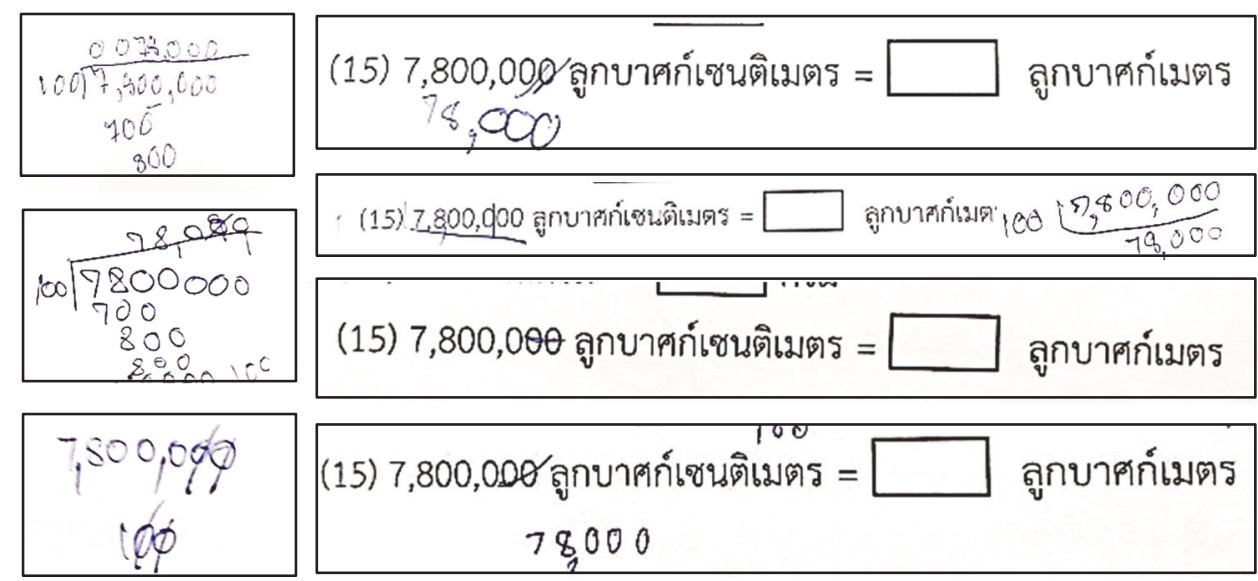

Figure 4. Examinees' Ideas from the Incorrect Answer

\section{Discussion and Conclusion}

In general, this study was designed to investigate the 139 students' mathematical competencies in terms of their knowledge and application. The results revealed that the majority of students are having problems in the content domain of Quantities and Measurements. Although the coverage of Quantities and Measurement content domain consisted of seven questions $(23.33 \%)$ out of 30 questions in the SUKEN test of level 6 but examinees had the lowest competency level to answer the related questions correctly (33.21\%) compared to other content domains. Besides, results also indicated that examinees possessed the least competency not only in the questions related to knowledge (38.49\%) but also its application $(31.09 \%)$ in Quantities and Measurement content domain. This result is consistent with the results of PISA 2012 that indicating Thai students had the greatest weaknesses in the content of change and relevance, and quantitative. Both topics are related to the Quantities and Measurement content domain. 
Moreover, the researchers continued to analyze specifically students' ideas in solving mathematical problems and managed to categorize them into seven groups of answers. The qualitative results showed that most of the students are having problems understanding the concepts of the relationship between units. Most of them used the concept of 100 centimeters $(\mathrm{cm})$ equal to 1 meter $(\mathrm{m})$ and then divided 100 centimeters $(\mathrm{cm})$ by 7,800,000 cubic centimeters $\left(\mathrm{cm}^{3}\right)$, which is found to be a unit of the different dimensions, that is, a centimeter is a unit of length while the cubic centimeter is a unit of volume. Since researchers are focusing on students' different ideas without making any judgment on whether the answers are correct or not as clarified by Inprasitha (2015), the students were required to answer the rationale of each idea (Manmai, Inprasitha, Changsri, \& Pattanajak, 2020).

The results imply that teachers are encouraged to use geometry to help students to have a better understanding of the relationships between the units. This implication is theoretically supported by previous studies (Kerr \& Lester,1976; The National Council of Teachers of Mathematics, 2000). Figure 5 illustrates an effective teaching practice by utilizing the geometry model to improve students' conceptual understanding of the relationship between units.

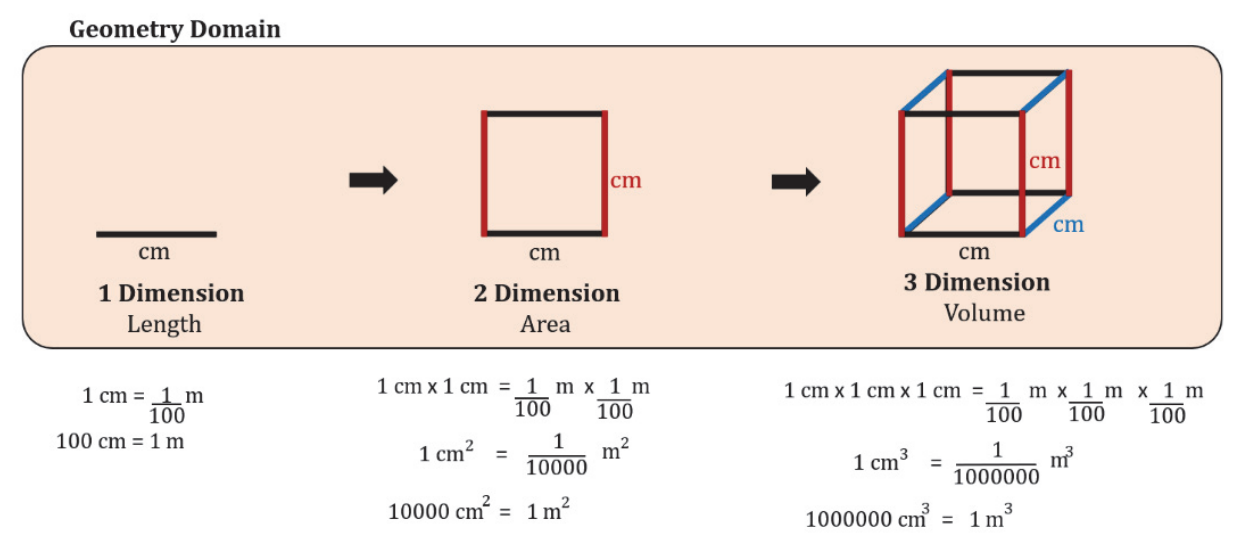

Figure 5. Using Geometry Domain to Understand the Relationship between Units

In conclusion, the overall results of this study have successfully contributed significantly to our recognition of the usefulness of large-scale assessment in providing substantial information to detect students' learning problems and determine an appropriate solution to improve teaching practices. On top of that, this major contribution is theoretically supported by Swan and Burkhardt (2012) who emphasized the importance of large-scale assessment in providing valuable messages to teachers regarding the relationship between instruction and assessment activities to improve students' mathematical competencies. Shimizu (2011) also supported the use of utilizing external or large-scale assessments to enhance teaching practices in Japan.

\section{Acknowledgments}

This research work was supported by the Centre of Excellence in Mathematics, The Commission on Higher Education, Thailand and the Centre for Research in Mathematics Education (CRME), Khon Kaen University, Khon Kaen 40002, Thailand. The contents of this manuscript are derived from the first author's doctoral dissertation thus fulfilling the Ph.D. requirement of Khon Kaen University.

\section{References}

Fan, L., \& Zhuo, Y. (2007). Presentation of problem-solving procedures: A comparative look at China Singapore, and US mathematics text- books. In T. Dreyfus (Eds.), Educational Studies in Mathematics (pp. 61-76). Berlin, German: Springer. https://doi.org/10.1007/s10649-006-9069-6

Inprasitha, M. (2015). The reform of curriculum and instruction system: Focusing on curriculum and evaluation. In Proceedings of the Korean Society of Mathematical Education 2015 International Conf. on Math. Edu. (Seoul Nat'l U.: November 6-8, 2015) 256-265.

Inprasitha, M. (2017). Mathematics competency test: Official guidebook. Khon Kaen, Thailand: Klungnana Vitthaya Press. [In Thai]

Inprasitha, M., Pattanajak, A., \& Inprasitha N. (2011). How do our teachers use our textbooks? Paper presented in APEC-Tsukuba International Conference. Tsukuba, Japan. Retrieved from 
http://www.criced.tsukuba.ac.jp/math/apec/apec2011/17-18/Thailandreport.pdf

IPST. (2014). PISA 2012 Assessment results mathematics, reading and science: What do students know? And what can be done. Bangkok, Thailand: Aroon. [in Thai]

Isoda, M. (Ed.) (2010). Elementary school teaching guide for the Japanese course of study mathematics (Grade 1-6). Tsukuba, Japan: CRICED University of Tsukuba. Retrieved from http://www.mext.go.jp/component/a_menu/education/micro_detail/_icsFiles/afieldfile/2009/04/21/126103 7_4.pdf

Kesorn, N., Junpeng, P., Marwiang, M., Pongboriboon, K., Tang, K. N., \& Wilson, M. (2020). Development of an assessment tool for mathematical reading, analytical thinking and mathematical writing. International Journal of Evaluation and Research in Education, 9(4), 955-962. https://doi.org/10.11591/ijere.v9i4.20505

Kilpatrick, J. (2009). The mathematics teacher and curriculum change. PNA, 3(3), 107-121.

Koehler, M. S., \& Grouws, D. (1992). Mathematics teaching practices and their effects. (pp.115-126). In D. A. Grouws (Ed.), Handbook of research on mathematics teaching and learning. Reston, VA: The National Council of Teachers of Mathematics.

Leher, R. (2007). Development understanding of measurement. In J. Kilpatrick, W.G. Martin, \& D. Schifter (Eds.), A research companion to principles and standard for school mathematics (pp.179-192). US: The National Council of Teachers of Mathematics.

Lincharoen, E., Artwichai, S., \& Chanin, P. (2009). Research report on causal factors causing low O-NET test scores of Grade 6 and 12 students. Retrieved from https://www.niets.or.th/th/content/download/279

Manmai, T., Inprasitha, M., Changsri, N, \& Pattanajak, A. (2020). Development of reasoning habits through Lesson Study and Open Approach Teaching Practices. International Educational Research, 3(2), 29-36. https://doi.org/10.30560/ier.v3n2p29

Niss, M. (1993). Assessment in Mathematics Education and its effects: An introduction. In M. Niss (Ed.), Investigations into assessment in Mathematics Education (pp.1-30). London: Kluwer Academic. https://doi.org/10.1007/978-94-017-1974-2_1

Senawongsa, C., Inprasitha, M., \& Sudejamnong, A. (2019). Teachers' learning in community of implementing mathematics textbooks with Lesson Study and Open Approach. Psychology, 10, 1636-1648. https://doi.org/10.4236/psych.2019.1012108

Santawee, B. (n. d.). Preparation for the teaching of science to ASEAN: A case study of PISA and O-NET [Online]. Retrieved from http://www.nstda.or.th/nac2013/download/presentation/Set4/SSH-Auditorium-01-03/07.pdf. [in Thai]

Shimizu, Y. (2011). Building bridges between large-scale external assessment and mathematics classrooms: A Japanese perspective. In B. Berinderjeet Kaur, \& W. K. Yoong, (Eds.), Assessment in the Mathematics Classroom Yearbook 2011. Singapore: World Scientific. https://doi.org/10.1142/9789814360999_0010

Swan, M., \& Burkhardt, H. (2012). A designer speaks: Designing assessment of performance in mathematics. Educational Designer: Journal of the International Society for Design and Development in Education, 2(5), 1-41. Retrieved from http://www.educationaldesigner.org/ed/volume2/issue5/article19

Tachibana, M. (2007). Teaching and assessment based on teaching guides. In M. Isoda et.al. (Eds.), Japanese Lesson Study in Mathematics - Its impact, diversity and potential for educational improvement. Singapore: World Scientific. https://doi.org/10.1142/9789812707475_0008

The National Legislative Assembly (2015). The system of curriculum and instruction development. [In Thai]

\section{Copyrights}

Copyright for this article is retained by the author(s), with first publication rights granted to the journal.

This is an open-access article distributed under the terms and conditions of the Creative Commons Attribution license (http://creativecommons.org/licenses/by/4.0/). 